\title{
O comportamento dos eventos de precipitação extrema e dos períodos de seca em São João do Tigre - PB
}

The behavior of extreme precipitation events and periods of drought in

São João do Tigre - PB

BARROS, L. A. R.; SOUZA, J. O. P.

Leticia_1.1@outlook.com

\begin{abstract}
Resumo
Este artigo tem como objetivo entender o comportamento e a recorrência dos eventos de precipitação e os períodos de seca no município de São João do Tigre - PB. Fazendo uso de uma metodologia baseado em cenários pluviométricos distintos baseados em anos secos, úmidos e regulares, nos quais os valores do volume de precipitações podem estar sobre influência de fenômenos atmosféricos como o El Nino ou a La Nina ou outros fenômenos que podem provocar o aumento ou diminuição a intensidade no volume de precipitação. Sendo possível classificar quais os anos foram mais secos ou quais os anos foram mais chuvosos, e quais os anos regulares. Para os dois postos pluviométricos analisados, observou-se um controle do aumento da altitude no aumento do volume total de precipitação. Contudo, a variação no volume total durante anos úmidos está ligada a variação na intensidade da chuva durante o período chuvoso, e não na diminuição dos meses secos no ano.
\end{abstract}

Palavras-chave: Comportamento da Precipitação, Períodos de seca, Cenários pluviométricos.

\begin{abstract}
This article has the objective to understand the precipitation behavior and the recurrence and drought periods in the municipality of São João do Tigre - PB. It was used a methodology based on different pluviometric scenarios, like as dry, wet and regular years. The values of the volume of precipitations might be affected of atmospheric phenomenon such as ENSO or other phenomena that may cause the increase or decrease the intensity in the precipitation volume. Therefore, it was possible classify what years were drier or did the years have been wetter there still also regular years. To the two pluviometric gauge analyzed, it was observed the control of the altitude increase in the increase of the precipitation total volume. Nevertheless, the variation of the total volume during the wet years it is related to variation of the rain intensity during the rainy season, rather in the reduction of dry months in the year.
\end{abstract}

Keywords: precipitation behavior, Periods of drought, Pluviometric scenarios.

\section{INTRODUÇÃO}

Levando em consideração a atual sequência e recorrência dos períodos irregulares de seca e dos períodos de grandes extremos chuvosos nas zonas semiáridas do Nordeste brasileiro, se faz necessário uma análise do comportamento das chuvas e dos períodos de seca, para que assim, seja possível entender e determinar quais alterações estejam ocorrendo nas zonas semiáridas.

Assim para compreender de forma correta o comportamento dos eventos de precipitação de uma região, foi necessário fazer uma analise com base no volume de precipitação de um determinado intervalo de anos classificando os anos através do valor gerado pelo cenário médio que serve como base para determinar o cenário seco, onde o ano tem um volume de precipitação menor ou igual que $25 \%$ no trimestre mais chuvoso, o cenário chuvoso possuindo um volume de precipitação acima ou igual a $75 \%$ no trimestre mais chuvoso, e o cenário regular que são os anos que não se adequaram em ambas as categorias anteriores (Varejão-Silva e Barros, 2001).

Leticia de Araújo Rocha Barros, Departamento de Geociencias, Laboratorio oficina de geografia da Paraiba - LOGEPA, Universidade Federal da Paraíba, João Pessoa -PB, Brasil

Jonas Otaviano Praça de Souza, Departamento de Geociencias, Laboratorio oficina de geografia da Paraiba - LOGEPA Universidade Federal da Paraíba, João Pessoa-PB, Brasil 
Desta forma é importante estudar o comportamento dos eventos extremos de precipitação e o comportamento dos períodos de seca na região para ajudar a prevenir problemas futuros como falta de água ou danos causados por um grande volume de precipitação como alagamentos, assim as alterações no volume e na intensidade das precipitações em uma determinada região podem causar vários problemas ambientais.

Os períodos de seca são irregulares, ou seja, nem sempre se pode prever com exatidão quando vai começar, ou quando vai acabar precisamente podendo prolonga-se por meses ou a até anos. Usando a visão meteorológica a seca é definida como o período durante o qual as chuvas de uma determinada região apresentam valores muito abaixo da normal climatológica, sendo assim, diferente de aridez já que não está relacionada com o volume absoluto de chuva (ACHEAMPONG, 1990). Ou seja, a aridez de uma região é determinada pela deficiência hídrica (DEF) que é a quantidade de água da chuva dividido pela evapotranspiração de referência ou potencial (ETP) que é a quantidade máxima de água da chuva perdida pela evaporação e transpiração, ou seja, quando o valor da evapotranspiração é superior ao valor das precipitações. Por outro lado, a seca está relacionada com o volume total de água da chuva, desse modo, quando esse valor é muito abaixo do normal para uma determinada região é assim determinado como um período de seca.

Já os períodos de extremos chuvosos, ou seja, períodos com precipitações intensas que são restringidos geralmente a um dia ou alguns dias em sequência num pequeno espaço de tempo, com um volume e uma intensidade de precipitação muito superior ao valor normal climatológico, tendo também o valor volumétrico de evapotranspiração menor que o volume total da chuva de uma determinada região, desse modo seus danos são ainda mais imprevisíveis, onde existe a presença de um grande volume de água em um curto espaço de tempo podendo causar danos a população, como alagamentos, e rompimentos de barragens (SOUZA e ALMEIDA, 2015).

Diante disso, é importante estudar e entender o comportamento dos eventos de precipitação extrema nas zonas semiáridas assim como os períodos de seca, levando em conta não apenas o volume total da precipitação anual, ou dados trimestrais e semestrais, bem como é realmente necessário fazer uso de dados diários, mensais analisando os meses individualmente e os dados anuais, observando também os eventos que fogem da normal, como por exemplo, por que ocorreu um evento extremo de precipitação em um período de tempo onde normalmente não tem um grande volume chuvas, ou um o período normalmente chuvoso teve um volume menor do que o previsto, alterando assim o comportamento normal das precipitações.

Várias questões podem alterar o comportamento das precipitações, podendo ser provocados por diferentes eventos naturais, dentre eles, estão o El Nino que é o aquecimento anormal das águas superficiais do Pacifico tropical provocando uma diminuição na precipitação e alterando os padrões 
dos ventos, o fenômeno atmosférico do El Nino-Oscilação Sul (ENOS) é caracterizado por fortes anomalias na temperatura da superfície do mar no pacifico equatorial, já o La Nina é o oposto do El Nino sendo o resfriamento das águas superficiais do oceano pacifica provocando aumento das precipitações.

O Dipolo do atlântico que pode tanto aumentar quanto diminuir as precipitações que é uma mudança na temperatura da superfície do oceano atlântico tropical, desse modo, quando as águas do atlântico norte estão mais quentes que as do atlântico sul ocorrem a inibição da formação de nuvens, diminuído as precipitações (dipolo positivo) no litoral brasileiro podendo provocar períodos de seca, Por outro lado, quando as águas do atlântico norte estão mais firas que as do atlântico sul, ocorre um aumento na formação de nuvens e nas precipitações (dipolo negativo), (OLIVEIRA, ALVES e NÓBREGA, 2010) podendo ser também influenciada pelo relevo, a exemplo do planalto na Borborema- PB onde ocorre uma barreira natural das precipitações.

Com o objetivo de analisar as mudanças nas características do comportamento e nos valores totais de precipitação na região do município de São João do Tigre, na Paraíba, seguindo a escala de tempo diária, mensal e anual, para determinar qual é o comportamento das precipitações em cenários de chuva anual diferenciados, médio, regular, úmido e seco. E a partir disso avaliar os eventos chuvosos e de seca.

Nos eventos de extremos chuvosos devem ser observados se existe alguma alteração no número de dias com chuvas, e nos valores totais da precipitação, destacando quais meses tiveram maior valor de precipitação. Nos eventos de seca é importante observar o número de dias sem chuvas, para assim analisar o valor do volume total da precipitação, se ocorreu mudança no nível de umidade, e em quais meses o número de precipitação foi menor.

\section{METODOLOGIA}

O município de São João do Tigre é localizado no semiárido paraibano fazendo divisa com o estado de Pernambuco, a bacia de Jucuru se encontra dentro dos seus limites correspondendo a cerca de $560 \mathrm{~km}^{2}$ e o município uma área de $816 \mathrm{~km}^{2}$. O índice pluviométrico médio anual da região é de $440 \mathrm{~mm}$, e sua variação altimetria é de 500 ate 1100 metros, aderindo a depressão intraplanáltica paraibana se estendendo até a cimeira estrutural Pernambuco-Alagoas (CORRÊA et al. 2010) fazendo parte do planalto da Borborema, na área referente ao limite PB/PE é existe um conjunto de serras altas, e os meses com o maior volume de precipitações são normalmente Março, Abril e Maio. 


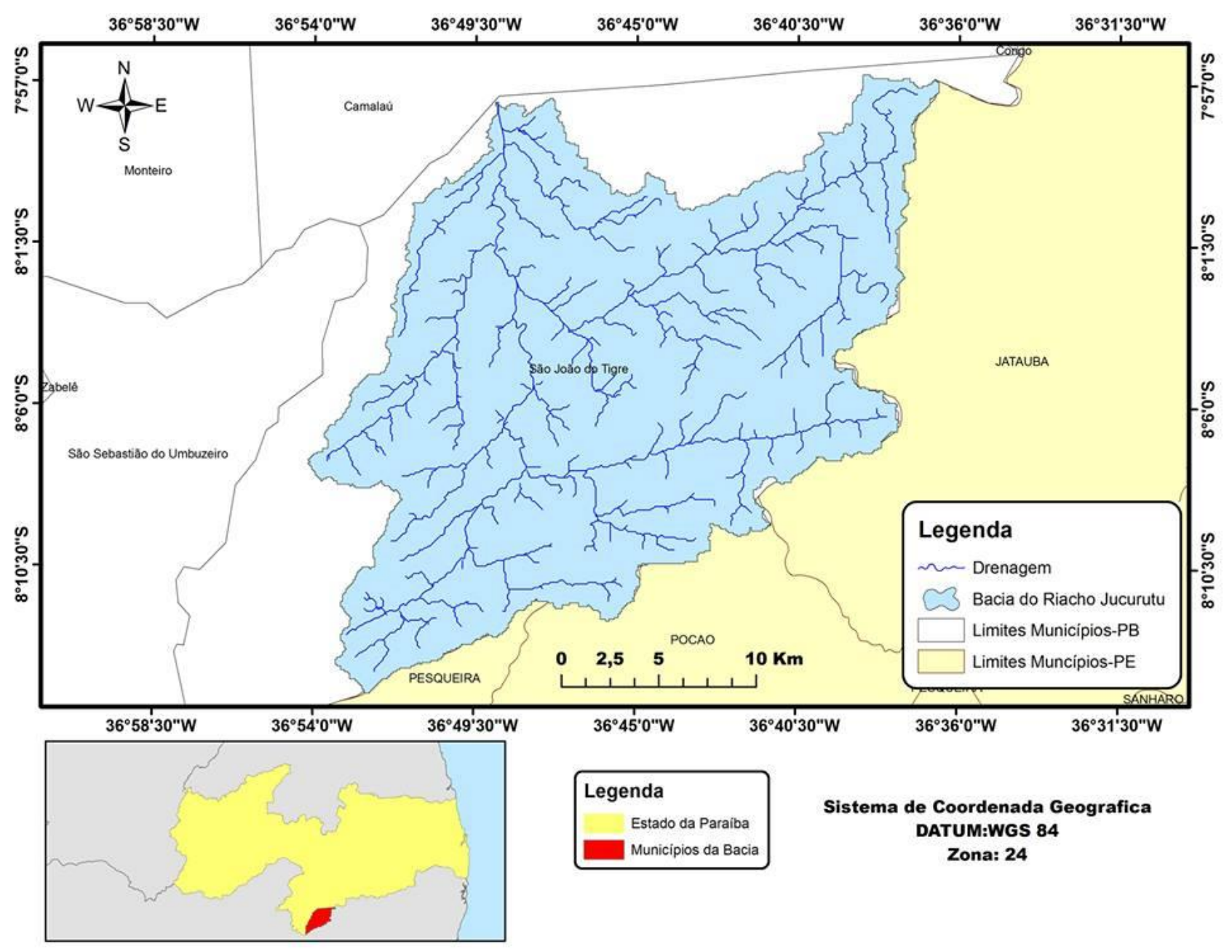

Figura 01: Mapa de localização, Autor: Santos, 2016.

Utilizando dados diários, mensais e anuais retirados das estações pluviométricas de São João do Tigre e Santa Maria ambas localizadas no município de São João do Tigre - PB, tendo como fonte a Agência Nacional de Águas (ANA) em um intervalo de 14 anos a partir 1994 até o ano de 2008, foi possível estabelecer um critério de classificação dos anos com base no volume total de precipitação, separando em cenário médio, seco, chuvoso e regular.

Cenário médio: São todos os dados disponíveis da estação pluviométrica calculados criando assim um valor médio anual de precipitação

Cenário seco: Constituído por anos nos quais o total de precipitação acumulada no trimestre mais chuvoso foi menor ou igual ao valor correspondente á probabilidade de chuvas em $25 \%$. Onde o volume de precipitação anual foi menor do que esperado tornando assim um ano seco.

Cenário chuvoso: Constituído por anos nos quais o total de precipitação acumulada no trimestre mais chuvoso foi maior ou igual ao valor correspondente à probabilidade de chuvas em $75 \%$. 
Cenário regular: Constituído por aqueles anos que não são classificados nas duas categorias anteriores, Ou seja, com um volume regular de precipitação (Varejão-Silva e Barros, 2001).

Desse modo os anos são classificados de acordo com os cenários anteriormente descritos, tendo como base o cenário médio que serve para determinar a classificação de todos os anos estudados, alguns em anos úmidos que são os anos incluídos no cenário chuvoso com um grande volume de precipitação, outros em anos secos onde o valor de precipitação foi muito baixo, fazendo parte do cenário seco e ainda os anos regulares, aqueles que não estão incluídos nas categorias anteriores.

Utilizando outros dados quantitativos como o número de dias sem chuva ou o número de dias com chuva, e dias consecutivos com chuva ou dias consecutivos sem chuva, para assim, entender o comportamento e determinar quais os meses possuem o maior ou menor volume de precipitação na região de São João do Tigre, e ainda fazendo uso do numero de dias com chuva efetiva e sem chuva efetiva, onde a chuva efetiva é aquela que é relevante para o sistema, nesse caso sendo qualquer chuva com o volume superior a $10 \mathrm{~mm}$. Além do total do volume de chuva anual e mensal, calculando também a média, a máxima e o valor mínimo das precipitações, gerando assim uma tabela com dados quantitativos do comportamento dos eventos de precipitação no município de São João do Tigre.

\section{RESULTADOS E DISCUSSÃO}

Os dados foram retirados de dois postos pluviométrico que apesar da sua localização próxima apresentam altitudes diferentes onde no posto de São João do Tigre está localizado na sede do município com $537 \mathrm{~m}$ de altitude apresentando volume média de precipitação anual de 440mm; e o posto de Santa Maria, localizado no distrito de mesmo nome, em uma altitude de 866m apresentando um volume médio de precipitação em torno de $750 \mathrm{~mm}$, sofrendo influencia direta do relevo o que resulta no posto com maior altitude ser também o posto com um maior volume de precipitação anual. A partir desses dados o comportamento da precipitação foi avaliada para os cenários médio, regular, seco e chuvoso.

Observando a dinâmica dos dados de São João do Tigre (tabela 01) onde para o período analisado (1994 até 2008) o volume máximo de precipitação anual é de 640 mm e o valor mínimo com $82 \mathrm{~mm}$, com um desvio padrão de $160 \mathrm{~mm}$ em relação ao volume de precipitação anual, os dias com chuva efetiva, ou seja, superior a $10 \mathrm{~mm}$ com máxima de 19 dias e mínima de dois dias 
chegando a ficar com media de 167 dias sem chuva efetiva, a chuva máxima pode chegar a $100 \mathrm{~mm}$ com mínima de $24 \mathrm{~mm}$.

Tabela 01. Dados pluviométricos de São João do Tigre. Fonte: Elaborado pelo autor (2016).

\begin{tabular}{|c|c|c|c|c|c|c|}
\hline & $\begin{array}{c}\text { VOLUME } \\
\text { ANUAL } \\
\text { (mm) }\end{array}$ & $\begin{array}{c}\text { DIAS COM } \\
\text { CHUVA }\end{array}$ & $\begin{array}{c}\text { DIAS } \\
\text { CHUVA } \\
\text { EFETIVA }\end{array}$ & $\begin{array}{c}\text { CHUVA } \\
\text { MÁXIMA } \\
\text { (mm) }\end{array}$ & $\begin{array}{c}\text { DIAS } \\
\text { CONSECUTIVOS } \\
\text { SEM CHUVA }\end{array}$ & $\begin{array}{c}\text { DIAS CONSECUTIVOS SEM } \\
\text { CHUVA EFETIVA }\end{array}$ \\
\hline MÁXIMO ANUAL & 648 & 50 & 19 & 100 & 159 & 223 \\
\hline MÍNIMO ANUAL & 82 & 15 & 2 & 24 & 51 & 102 \\
\hline DESVIO PADRÃO & 161 & 10 & 5 & 23 & 36 & 167 \\
\hline CENÁRIO MÉDIO & 437 & 35 & 13 & 61 & 107 & 181 \\
\hline $\begin{array}{c}\text { CENÁRIO } \\
\text { CHUVOSO }\end{array}$ & 550 & 40 & 15 & 64 & 108 & 203 \\
\hline CENÁRIO SECO & 269 & 22 & 8 & 45 & 124 & 153 \\
\hline $\begin{array}{c}\text { CENÁRIO } \\
\text { REGULAR }\end{array}$ & 423 & 36 & 13 & 63 & 103 & \\
\hline
\end{tabular}

Diante da perspectiva dos cenários climatológicos foi possível entender o comportamento das precipitações no cenário médio o volume de precipitação está em torno dos $440 \mathrm{~mm}$ com chuva máxima na casa dos $60 \mathrm{~mm}$, dentro do cenário chuvoso, ou seja, anos mais úmidos o volume médio é de $550 \mathrm{~mm}$, no cenário seco os anos com menor volume de precipitação podendo ter sofrido influencia de fenômenos como o El Nino, o volume de precipitações com um volume médio de 260 mm, ainda no cenário regular, aqueles anos que não se encaixam em outros cenários o volume está em torno de $420 \mathrm{~mm}$.

Observando os dados de Santa Maria (tabela 02) no qual o volume máximo de precipitação anual é de $730 \mathrm{~mm}$ e o valor mínimo com $260 \mathrm{~mm}$, com um desvio padrão de $230 \mathrm{~mm}$ em relação ao volume de precipitação anual, os dias com chuva efetiva, ou seja, superior a $10 \mathrm{~mm}$ com máxima de 40 dias anuais e mínimo de 10 dias chegando a ficar com media de 97 dias sem chuva efetiva, a chuva máxima pode chegar a $140 \mathrm{~mm}$ com mínima de $28 \mathrm{~mm}$.

Seguindo ainda a perspectiva dos cenários climatológicos foi possível entender o comportamento das precipitações no cenário médio o volume de precipitação está em torno dos 730 mm com chuva máxima na casa dos $70 \mathrm{~mm}$, dentro do cenário chuvoso, ou seja, anos mais úmidos o volume médio é de $820 \mathrm{~mm}$, no cenário seco os anos com menor volume de precipitação com um volume médio de $560 \mathrm{~mm}$, ainda no cenário regular, aqueles anos que não se encacham em outros cenários o volume está em torno de $760 \mathrm{~mm}$. 
Tabela 02. Dados pluviométricos de Santa Maria. Fonte: Elaborado pelo autor (2016).

\begin{tabular}{|c|c|c|c|c|c|c|}
\hline & $\begin{array}{c}\text { VOLUME } \\
\text { ANUAL } \\
\text { (mm) }\end{array}$ & $\begin{array}{c}\text { DIAS COM } \\
\text { CHUVA }\end{array}$ & $\begin{array}{c}\text { DIAS CHUVA } \\
\text { EFETIVA }\end{array}$ & $\begin{array}{c}\text { CHUVA } \\
\text { MÁXIMA } \\
(\mathbf{m m})\end{array}$ & $\begin{array}{c}\text { DIAS CONSECUTIVOS } \\
\text { SEM CHUVA }\end{array}$ & $\begin{array}{c}\text { DIAS CONSECUTIVOS SEM } \\
\text { CHUVA EFETIVA }\end{array}$ \\
\hline $\begin{array}{c}\text { MÁXIMO } \\
\text { ANUAL }\end{array}$ & 1089 & 68 & 40 & 141 & 104 & 136 \\
\hline $\begin{array}{c}\text { MÍNIMO } \\
\text { ANUAL }\end{array}$ & 261 & 22 & 10 & 28 & 45 & 24 \\
\hline $\begin{array}{c}\text { DESVIO } \\
\text { PADRÃO }\end{array}$ & 237 & 12 & 9 & 26 & 17 & 97 \\
\hline $\begin{array}{c}\text { CENÁRIO } \\
\text { MÉDIO }\end{array}$ & 752 & 44 & 29 & 70 & 77 & 105 \\
\hline $\begin{array}{c}\text { CENÁRIO } \\
\text { CHUVOSO }\end{array}$ & 819 & 46 & 33 & 87 & 71 & 88 \\
\hline $\begin{array}{c}\text { CENÁRIO } \\
\text { SECO }\end{array}$ & 564 & 39 & 23 & 54 & 66 & 79 \\
\hline $\begin{array}{c}\text { CENÁRIO } \\
\text { REGULAR }\end{array}$ & 765 & 44 & 28 & 66 & & 95 \\
\hline
\end{tabular}

De forma geral é possível notar a diferença no volume anual de precipitação onde o posto de Santa Maria possui uma altitude maior e um volume médio de $730 \mathrm{~mm}$ enquanto São João do Tigre, com uma menor altitude possui uma média de $440 \mathrm{~mm}$ anuais, influenciando também nos dias consecutivos sem chuva efetiva, onde o posto de São João do Tigre dento do cenário médio teria 167 dias enquanto o de Santa Maria 97 dias, assim como o número de dias com chuva efetiva onde a máxima no posto de São João do Tigre foi de 19 dias e em Santa Maria 40, ou seja, o posto de Santa Maria registrou um maior numero de dias com chuva efetiva.

\section{CONSIDERAÇÕES FINAIS}

Os Postos de São João do Tigre e o de Santa Maria apesar de sua proximidade apresentam 329 metros de diferença altimétrica, o que reflete diretamente o aumento dos volumes de precipitação para o posto de Santa Maria; representando as áreas mais elevadas da bacia estudada. A influência do relevo na precipitação é evidente tanto nos volumes totais como no aumento da intensidade de chuvas.

Contudo, ao avaliar a variação entre os cenários para cada um dos postos observa-se que o que a principal característica da precipitação que controla a variação do volume total de precipitação está relacionada com a intensidade da chuva. Visto que o aumento do volume total não se reflete proporcionalmente no aumento dos dias de chuva (normal e efetiva) e nem na diminuição 
dos períodos anuais de seca, representados pelos índices de dias consecutivos sem chuva (normal e efetiva). Dessa forma, esse aumento do volume de precipitação

Diante da grande complexidade da topografia na região de São João do Tigre onde ocorrem grandes variações na altitude e devido à presença de poucos e insuficientes postos e estações pluviométricas para coleta de dados na região, obter os dados foi uma pesquisa complexa, alguns pontos da bacia estão localizados a mais de $30 \mathrm{~km}$ dos postos de coleta de dados.

E ainda existe a presença de chuvas convectivas locais com poucos quilômetros de diâmetro, ou seja, chuvas localizadas em uma área com curta extensão, as quais podem não serem registradas por falta de postos e estações.

\section{REFERÊNCIAS}

ANDRADE JÚNIOR, A. S. Classificação climática e regionalização do semiárido do Estado do Piauí sob cenários pluviométricos distintos. Revista Ciência Agronômica, Fortaleza, v. 36, n. 2, p.141-151, maio agosto 2005 .

CORREAA, A. C. B.; TAVARES, B. A. C. Megageomorfologia e morfoestrutura do planalto da borborema, Revista do Instituto Geológico, São Paulo, 2010, P. 35-52.

SOUZA, J. O. P.; ALMEIDA, J. D. 2015. Caracterização e espacialização da precipitação em bacia hidrográfica com relevo complexo: sertão central pernambucano - Bacia do Riacho do Saco, Revista de Geografia (UFPE) V. 32, No. 2, 2015 .

VAREJÃO-SILVA, M. A.; BARROS, A. H. C. Zoneamento de aptidão climática do estado de Pernambuco para três distintos cenários pluviométricos. Recife: COTEC/DATA AGROS/ SPRRA-PE, 2001, 38p.

Recebido em: 14/08/2016

Aceito para publicação em : 01/10/2016 